\title{
A Dialectical Perspective to Research Paradigms in Mixed Methods Research in Curriculum Enactment
}

\author{
Patricia A. L. Ong (University of Waikato)
}

Dialectics is used as an approach to address divergent data and results when bringing together paradigms with conflicting theories (Greene \& Hall, 2010). The dialectic approach provides a framework for managing and the analysis of data, the relationship between researcher and participants and dialogues across the various paradigmatic worldview perspectives. It places equal emphasis on different groups with not hierarchal structure and is therefore an ideal approach to utilize when place an equal priority on various data strands and groups in a mixed methods study ( Johnson \& Stefurak, 2013). In bringing together two or more worldviews or paradigms into the research process, a dialectic perspective also looks at the tensions that arise as a consequence. Mixed methods research (MMR) facilitates the validity of findings by grounding through them in multiple perspectives, multiple participants and methods (Guba \& Lincoln, 2005; Mertens, 2015). The purpose of this paper is to acknowledge the rationale of a dialectical perspective used in MMR and the role of philosophical worldviews and assumptions underlying MMR. It summarizes findings from a mixed methods study using visual netnography, ethnographic observations, interviews and a survey questionnaire and discusses possible implications in practice, teacher education and professionalism within the context of curriculum enactment in early childhood education settings.

Key words: dialectics, research paradigms, mixed methods research, curriculum enactment.

\section{Introduction}

The recognition of a paradigm as a means by which scientists and researchers made sense of their world and reality was acknowledged by Kuhn (1962). The concept of a paradigm shift demonstrated the transience of paradigm development that was moulded by societal and scientific change and evolution. Based on traditionally long-held philosophical perspectives, there were two main philosophical approaches on the two ends of the ontological continuum of reality and this was either 'positivist' or 'interpretivist'. It was only in the 1970s and 1980s when there was a debate on the feasibility of combining both qualitative and quantitative 
approaches and it was only in late 1980s that Greene, Carcelli and Graham (1989) laid the groundwork for mixed methods research and the adoption of multiple philosophical worldviews (Creswell \& Plano Clark, 2017).

\section{Research Paradigms}

The four philosophical worldviews or research paradigms are discussed here to provide the underlying philosophical assumptions for the research design. The contention, is that methodological and epistemological pluralism in educational research is becoming increasingly valuable as research contexts become more complex, interdisciplinary and dynamic (Burke Johnson \& Onwuegbuzie, 2004). However, each of these individual philosophical worldviews or research paradigms should be examined on its own.

\section{Postpositivist}

The postpositivist paradigm is most representative of traditional research and the assumptions here hold true more for quantitative research. This is also positivist or scientific research but the term 'postpositivist' represents the challenge towards 'absolute truth' and it tends to be deterministic and reductionist in its philosophy in its attempt to reduce concepts and ideas to small and discrete sets. As it is based on empirical observation and measurement of variables, the use of survey for example is a method that has its basis in postpositivism or postempiricism. Developing numeric measures of observations through frequency counts, statistical analysis and other measures become imperative for the postpositivist (Phillips, 2000; Willis, 2012). From the epistemological perspective, objectivity, impartiality and distance is maintained between the researcher and that being researched. Postpositivism has developed from positivism or empiricism and is similar in many aspects (Creswell, 2014; Willis, 2012). While positivism or empiricism is seen as an accurate reflection of reality, the postpositivist perspective is that there may never be one truth or objective reality because you cannot discover the truth or one objective reality through just one study. While positivists develop theory 
through the scientific approach, postpositivist test theory through the scientific research. The postpositivist paradigm searches for universal beliefs, concepts and ideas that are applicable to many different situations (Ryan, 1999). This form of research is to find 'universal statements' can be used to generalize across different contexts.

\section{Constructivism}

The constructivist or social constructivist perspective is often combined with interpretivism holds the worldview that meaning is constructed and is subjective (Creswell \& Plano Clark, 2011). These subjective meanings are formed and negotiated through the interactions with others and through the historical and cultural experiences of the individual (Creswell, 2014). Several assumptions operate based on this paradigm (Crotty, 1998; Guba \& Lincoln, 2005). Firstly, individuals construct meaning as they engage and interact with the world and context that are in. Based on this premise, the qualitative researcher will use open-ended questions so that participants share their views based on their historical and social perspectives and experiences (Halldén, Haglund, \& Strömdahl, 2007). Next, the researcher's own experiences and background also shapes his or her interpretation of the findings. The final assumption is that the process of qualitative research is inductive as researcher generates meaning from the data that is collected. Meanings or interpretations derived from the participants, data are multiple, varied, and there is a convolution and complexity of views rather than a narrow limited interpretation of things (Reissner, 2017). Constructivist paradigms offers the window for challenging established research paradigms and introducing alternative paradigmatic directions (Grand, von Arx, 2015). There is a spectrum of constructivist epistemologies that differ on certain premises but the commonality shared is a scepticism taken for granted and unquestioned concepts and practices and also in the generating explanations and making reinterpretations (Hacking, 1999). In eliciting perspectives and views of various practitioners, 
the interpretation, meaning and significance of various possibly conflicting viewpoints are coconstructed and juxtaposed in the constructivist research paradigm.

\section{Transformative}

The transformative or participatory worldview paradigm used in research inquiry is quite often influenced by political concerns and like the constructivist worldview is often associated with qualitative approaches (Creswell, 2014; Creswell \& Plano Clark, 2011). However, the transformative paradigm may include some quantitative component as in mixed methods research. In terms of axiology, there is usually an agenda in the area of social justice or human rights that may include issues such as inequality, oppression, and marginalization and possibly others that need to be addressed (Mertens, 2010). There is a need for respect for cultural norms during interactions and this paradigm usually goes to advocate an agenda for a marginalized or minority groups of individuals. Ontologically, the transformative worldview rejects cultural relativism and acknowledges that there are multiple realities that are moulded by inequities from social, political, cultural, economic, gender, ethnic, disability and other values (Mertens, 2007). It also recognizes the power imbalance resulting from such inequities. The transformative paradigm is often adopted by critical theorists, interventionists and is change orientated. It is usually participatory in nature and there is an interactive connection between the researcher and participants and the inquiry is collaborative so that they are not marginalized further ( Creswell, 2014; Creswell \& Plano Clark, 2017).There is an active involvement of participants in constructing realities with the consideration of participants' values and belief during the process. The inclusion of a qualitative approach that is mainly dialogic is essential while quantitative or overall mixed methods may be adopted (Mertens, 2010). Epistemologically, the assumption is that the close collaboration between the researcher and the participants will facilitate the development of research purpose, design and implementation that is culturally appropriate. The transformative axiological assumption reflects an awareness 
of the presence of discrimination that exist in many communities and so the there is an ethical responsibility to be aware and understand the critical aspects of diversity, in order to challenge the processes that continue an oppressive status quo (Mertens, 2015). The ontological assumptions of the transformative paradigm is that it acknowledges the multidimensional nature of reality. The concept of what constitutes reality is influenced by the positionality of the individual. An individual in a position of unmerited privilege by virtue of gender, ethnic group or disability may experience one version of reality whereas an individual in a position of disadvantage that is not of a privileged position may hold another version of reality. The transformative paradigm's philosophical assumptions are aimed for the researcher to place an emphasis for the cause of social justice (Mertens, 2007, 2010). In looking in the context of how the curricula that is being enacted, also the challenges faced by early childhood practitioners in Singapore, the question of whether the cultural diversity as well as possibly marginalized subgroups are being given a voice has to be considered in the processes of data collection, analysis and interpretation.

\section{Pragmatism}

The premise on which pragmatism is qualified as a philosophical framework for social research is that it not only is able to demonstrate as a philosophical system but also serves with its practicality for issues such as research design and also that of the agenda of social justice (Morgan, 2014). Pragmatism as a paradigm tends to goal or problem orientated. Ontologically, there is no construction of a single or multiple reality but real life issues and practice influence the methods and approaches that 'best solve the problem' (Creswell, 2014). The pragmatist framework allows the possibility for multiple methods, different worldviews and perspectives, assumptions and different forms of data collection and analysis. Thus, the pragmatist worldview attempts to work with the tensions and differences between the different worldviews, integrating them towards the goal. It is a relative new paradigm that emphasis the 
known Deweyan concept into research inquiry and provides for practicality (Dewey, 2008). Deweyan pragmatism is based on the assumptions about the nature of human experience and that our understanding and interpretation of our own experiences influences our consequent actions on these beliefs. Based on the theories of John Dewey, the pragmatist paradigm integrates beliefs and actions into the process of inquiry and pursuit of knowledge through the activity termed research. For the pragmatist researcher, there is an emphasis on the experiences as a continual interaction of beliefs and actions and not a specific ontological or epistemological stance taken toward research practice. The paradigmatic shift towards pragmatism and its association with mixed methods research emphasizes the practical and procedural issues on how to effectively combine the strengths of qualitative and quantitative methods rather than on the philosophical assumptions and claims (Christ, 2013; ShannonBaker, 2016). This is different from the traditional lens of viewing social research in terms of ontology, epistemology and methodology. Also, the other pragmatist worldviews offers a utilitarian approach to the research which is another dimension as opposed to the other worldviews such as the transformative paradigm that prioritizes social justice and equity and is rights-based in nature (Mertens, 2015). As will be iterated later, the pragmatist worldview is results focussed and requires that practical solutions for some of the issues and challenges raised in the course of the study are developed (Shannon-Baker, 2016; Tashakkori \& Teddlie, 2010)

\section{Dialectics of Multiple Worldviews}

Ontologically, the study can be said to be positioned between the postpositivist and interpretative ends of the research continuum as there was a felt need to utilize an objective and scientific approach, yet validate the many voices and interpretations due to the complexity of the context and viewpoints of the participants in the study (Creswell \& Plano Clark, 2017; Edmonds \& Kennedy, 2013; Mertens, 2010). Hence, a combination of qualitative and 
quantitative methods was decided upon and this pointed in the direction of a mixed methods study. However, as the study progressed, several other issues developed from the initial inquiry. Traditionally, it has been vital to align one's research to the most appropriate paradigm or one 'best world view' in educational research. There is a rationale and justification of the choice of a paradigm based on the assumptions, beliefs and ethical considerations made (Guba \& Lincoln, 2005; Shannon-Baker, 2016). Contrary to the one 'best worldview' position, there are a few other stances that the researcher may adopt, including 'multiple worldviews in mixed methods', 'worldviews related to the type of mixed methods design' or worldviews depending on the scholarly community (Creswell \& Plano Clark, 2017, pp. 45-47). In adopting a multiple worldview position, these paradigms give rise to tensions and opposing concepts that reflect the various forms of ontological, epistemological and axiological stances which also reflects the postmodernist stance of this study (Christ, 2013; J. Creswell \& Plano Clark, 2017; Denscombe, 2008).

The study began with several broad research questions into the enactment and challenges of the curriculum in early childhood setting in Singapore. With the broad objectives that were initially outlined at the commencement of the study, it was decided that an exploratory sequential approach was to be adopted. The initial qualitative phase and literature review provided the basis and direction of the survey questionnaire in the subsequent phase of the study. The first phase began with a qualitative approach based on scheduled centre visits, open house visits, conversations and interviews with various educators and also a document analysis of the curriculum and policy framework of the national curriculum documents. Secondary data was also used, gathered from social media networking sites of various centres to gain various perspectives of what constituted the curriculum in the research setting. In this phase, the objective was to co-construct various perspectives and realities of what constituted the curriculum in different contexts and to attempt to define the boundaries of the research setting. 
Thus, the first phase of the study was positioned mainly within the constructivist-interpretivist paradigm. A largely inductive approach using a constructivist grounded data analysis approach was used to determining and building patterns, themes and the general conceptual framework for the study with the qualitative data findings as well as the secondary data from social media sites. A quantitative component can be said to be embedded in the first qualitative phase of this study (Shannon-Baker \& Edwards, 2018). Based on the results and themes derived from the qualitative analysis, the information was to be used to design the quantitative instrument in the form of a survey questionnaire. The focus during the centre visits, field observations and conversation interviews with teacher participants was on the kinds of approaches that was used in the curriculum. However, there was quite a variety of possibilities that were mentioned so several questions in the survey included that on the types of curriculum and documentation approaches that the teacher participants were familiar with. As the first phase of the study involved a relatively small number of participants from a limited number of centre settings, the survey questionnaire was targeted at a larger population sample. This was to find out through the quantitative component in the second phase if the initial qualitative results could be corroborated to a larger sample in the subsequent quantitative phase (Creswell, 2015). Epistemologically, the quantitative survey created distance and impartiality and provided objective data that was interpreted and substantiated with the qualitative data findings (Creswell \& Plano Clark, 2017; Willis, 2012)

It can be said that multiple worldviews or a pluralistic stance and the representative model due to the blended approach where both etic and emic perceptions coexist in the study is one which consists of multiple research paradigms on a continuum. The transformative-emancipatory worldview (Shannon-Baker, 2016) arises in the dialectic with practitioners who have a strong advocacy for a cause in their position regarding specific issues and concerns such as 'the need for a more inclusive approach towards learners with special needs' or for greater 'teacher 
professionalism'. The pragmatist worldview from my perspective is necessitated by the outcome-orientated and communicative aspects of this research study that requires practical solutions to be created for the challenges and issues raised (Shannon-Baker, 2016; Tashakkori \& Teddlie, 2010).

\section{Communities of Practice and the Dialectical Perspective}

A community of practice usually refer to a group of individuals who share an interest in a domain of human endeavour and engage in a process of collective learning that creates bonds between them (Wenger, 1999, 2001). Members of the community develop a set of shared repertoire of resources: experiences, tools, stories and ways of addressing recurring or common issues and challenges that in short is a shared practice. The concept of communities of practice has both practical and theoretical implications. Theoretically, it may serve as a unit of analysis to better understand processes that involve the engagement of participants with broad issues such as culture, identity and meaning in context. I would like to highlight the influence of the pragmatist worldview which is characterized by an emphasis on shared meaning-making and communication so as to come up with practical solutions as a consequence of the study (Shannon-Baker, 2016). The other aspect of pragmatism in this study is the possibility of transferability to consider the implications of research. In the qualitative phase, transferability suggests possible local and external connections that data can reveal about a phenomenon or whether knowledge we have gain can be transferred to other settings (Mertens, 2007; ShannonBaker, 2016).

In terms of research practice and pragmatism as a research paradigm, the concept of communities of practice thus helps to bind several characteristics. Firstly, there are shared issues and specific challenges that are face by communities of practice. Shared practice and a shared identity are common to members of such communities and finally, the paradigm operates through groups of practitioners who through their interpersonal networks can come 
to collaborate with others who face similar issues and challenges (Denscombe, 2008; Morgan, 2007). Through shared learning and mutual collaboration, the key issues, challenges and questions are generated even as members develop shared distinctive practices, repertoires, resources and language.

The transformative-emancipatory worldview paradigm comes with the deliberate collaboration with minority or marginalized groups whose voice is not always readily heard on particular issues. This perspective emphasizes on the agenda to increasing awareness on issues that are related to race, class, disabilities or a marginalized group and often makes explicit the researchers' values, ethics and worldviews (Creswell \& Plano Clark, 2011; Mertens, 2010). Thus, despite being viewed in the light of communities of practice often with shared views and identities, there are still a small number of individuals who feel a need to voice their opinions and perspectives on certain issues and concerns that are brought up in the process of the research study.

Moreover, it may be problematic if inferences and analysis from qualitative and quantitative data that come from samples at different levels of the organization or bureaucracy are used for triangulation unless the purpose of the researcher is to highlight the differences between these two groups. In order to adopt the transformative-emancipatory perspective, it is critical or the researcher to have deep understanding of the community and its social-historical contexts (Creswell \& Plano Clark, 2011). Within the transformative paradigm, it is critical to frame all decisions, data collection, analysis and interpretation within the cultural, social and historical contexts of the community. Particular attention has to be paid to the issues of power, privilege and voice and this worldview provides mixed methods research central objectives to guide the research process (Shannon-Baker, 2016). 
In bringing together two or more worldviews or paradigms into the research process, a dialectic perspective looks at the tensions that arise as a consequence. Dialectics is used as an approach to address divergent data and results when bringing together paradigms with conflicting theories (Greene \& Hall, 2010). The dialectic approach provides a framework for managing and the analysis of data, the relationship between researcher and participants and dialogues across the various paradigmatic worldview perspectives. It places equal emphasis on different groups with not hierarchal structure and is therefore an ideal approach to utilize when place an equal priority on various data strands and groups in a mixed methods study (R. B. Johnson $\&$ Stefurak, 2013).

\section{Rationale of the Mixed Methods Research}

There were several reasons justifying the use of mixed methods research in the study and these included that of obtaining more rigorous conclusions by offsetting the strengths and weaknesses of qualitative and quantitative methods (Onwuegbuzie, 2012), the complementary aspects (Tashakkori \& Teddlie, 2010) of each method that was able to elucidate different aspects of a phenomenon and obtaining more credible conclusions by grounding them in multiple perspectives through multiple methods, participants and theories (Clark \& Ivankova, 2018; Mertens, 2010). The use of the preliminary findings from the qualitative first phase of this exploratory sequential study facilitated the development of the quantitative survey instrument in the subsequent phase of the study (Creswell \& Plano Clark, 2017). This balance of both qualitative and quantitative methods has a pragmatic component in discovering and challenging issues of inequity and oppression (Clark \& Ivankova, 2018; Morgan, 2014).

Mixed methods research has emerged as an alternative between the two opposing and contrasting epistemological positions which is objectivism or postpositivism and subjectivism or constructivism (Creswell, 2015). There are three main mixed methods used in social sciences and educational research (Creswell, 2015; Edmonds \& Kennedy, 2013). The first 
model is convergence parallel mixed methods. In this model, both quantitative and qualitative data are collected at the same time and the data from both sources are merged in the interpretation of the overall results (Agarwal, 2011). The second model is the explanatory sequential mixed methods: this is when the researcher conducts the quantitative research first and then based on the analysis of the results, goes into the qualitative stage of the study in order to explain the initial quantitative findings (Crouch \& McKenzie, 2006). The third model that is the exploratory sequential model which is the model from which the basic design of this study is based on (Ballesteros \& Mata-benito, 2018). The first qualitative phase provides the data that is analysed and interpreted in order to build and design the instrument for the second quantitative phase. The challenge in this particular mixed methods design is in selecting the appropriate qualitative findings to focus on in order to develop the second phase instrument.

More complex and advanced mixed methods models are derived from these basic models and these include the transformative and embedded mixed method design (Shannon-Baker, 2016). Based on the multiple worldview /paradigms perspective as opposed to the one best worldview/paradigm position, a social justice lens may be adopted in a transformative mixed method design with a dialectical perspective (Mertens, 2007; Shannon-Baker, 2016). In this study, an embedded design involved the use of visual data derived netnography embedded in the largely qualitative research design and the conversion of visual data into quantitative data (O’Connell, 2013; Shannon-Baker \& Edwards, 2018).

\section{Methodology}

The mixed methods research approach involves both qualitative and quantitative data collection and in this study a number of diverse sources of data are used (Tashakkori \& Teddlie, 2010). The data collection process in mixed methods research consists of several key aspects including sampling, gaining permissions and consent, collecting data, recording data and administering data collection (Creswell \& Plano Clark, 2017). As the research design with an 
exploratory sequential approach requires two different sample population at each phase, there was some deliberation of the appropriate sample size for the quantitative survey stage. Different population samples were used in the qualitative and quantitative components of the study and the survey instrument was designed after sufficient qualitative data was gathered, coded and analysed to provide the themes that were to be covered by the survey. The main methods, both qualitative and quantitative are outlined.

\section{- Visual Netnography}

Visual netnography is an online research method that originates from the terms 'visual ethnography' and 'the internet' (Kozinets, 2006). It is qualitative research approach that adapts traditional ethnographic techniques to online methods, communities, practices and cultures that have been created through computer- or internet-mediated communications (Addeo, Delli Paoli, Esposito, \& Ylenia Bolcato, 2019). However, in this study, a quantitative component was embedded. Visual research methods have been said to be not purely 'visual' but place emphasis on visual aspects of culture, not to used independently of other methods (Sarah Pink, 2011). Ethnography in the 'Netnography' in this instance can be viewed as a process of constructing and representing knowledge (about a phenomenon, an aspect of a society, culture and individuals) and may represent only the ethnographer's version or form of reality (Stocchetti, 2017).

\section{- Interviews}

Interviews, both semi-structured and open-ended interviews were decided as one of the main methods of the study as it is particularly useful when obtaining detailed perspectives, elicit opinions on sensitive topics and a greater depth of information from informants in 'privileged' positions can be obtained (Denscombe, 2010; Willis, 2019). The interviews were mostly audio-recorded with the consent and knowledge of the interviewee. 
As one of the methods adopted in an ethnographic study, there was a component of observation that was either participant or non-participant in scheduled centre visits. There was a adoption of a continuum of forms of interviews that included ethnographic (combined with observation) (Schensul, Shensul, \& LeCompte, 2013), informant (no visit to centre or observation) (Tracy, 2013) and narrative (partly phenomenological) interviews types (Atkinson, 2002). Although an interview protocol guide was prepared to be used in the interviews with teacher participants, the interview forms ranged between a semi-structured to a more open-ended unstructured form as the participants sometimes talked about issues and aspects of their practice that were outside the scope of the interview questions (Brinkmann, 2013).

\section{- Participant-generated data}

It has been acknowledged that data generated that is not solely language-based may be more inclusive and offer alternative ways of expressing and describing their experiences and perspectives (Kortegast et al., 2019; Literat, 2013; S. 1 Pink, 2007). The engagement with an approach that allows the collaborative use of participant-generated data allow for empirical and first-hand opportunities for the researcher and participants to co-construct meaning, knowledge, context and identities from emic and etic perspectives (Keller, Fleury, Perez, Ainsworth, \& Vaughan, 2008). Participant-generated data is part of the researcher-participant collaborative process and this can provide a very direct and literal representation of the participant's viewpoints, the contexts and also be a creative outlet for reflective practice (Liebenberg, 2009; Pfister, Vindrola-Padros, \& Johnson, 2015). Collaborative and participatory research facilitates the process of demystifying and democratizing the research process and disrupts the power imbalance that is found in many research environments (Schensul et al., 2013).

In the context of this study, the participants were invited to share their experiences and approaches with the ECE curriculum through the use of artefacts such as their pupils' work 
samples, their own assessment documentation, photo or video clips, reflective logs and displays in the classroom. Some of the dialogue and conversation between the participant and myself were partly based on these participant-generated artefacts so that there was a co-construction of meaning and significance of their experiences in their own classroom and centre settings (Liebenberg, 2009). This was possible with follow-up communication with participants as well through various multi-modal communication that also facilitated the further exploration of research themes and the participatory analysis of visual data (Pfister et al., 2015).

\section{- The Survey Questionnaire}

The survey questionnaire was designed based on some of the key themes found in the qualitative semi-structured and open-ended interviews and dialogues with educators in the field. It was also framed based on some other similarly structured ethnographic research data from studies done in the context of Singapore and from the literature review of studies with parallel objectives in New Zealand (Bautista, Ng, Múñez, \& Bull, 2016; Bautista, Wong, \& Gopinathan, 2017; Mitchell, 2008). Through the interviews and conversations with early childhood educators, the critical ethnographic domains in the focus of this study. These would help to define the range of variation in knowledge, practices, attitudes, social organizations in the defined cultural group (Schensul et al., 2013).

The key questions in this ethnographic survey were mainly close-ended which may allow an open-ended response if the respondent selected the option of 'Other' from the given options and also the use of ranking and rating items (Schensul et al., 2013). It also integrated questions and instruments derived from other studies as mentioned earlier, the purpose and strength of the designed survey was to describe in an ethnographic context, the variation of elements of the social-cultural context of early childhood settings found in Singapore (Bautista et al., 2016; Mitchell, 2008; Schensul et al., 2013). The data that is obtained from the survey findings do not stand alone but are used with other data sources including the qualitative interview findings 
so as to provide a more comprehensive picture of early childhood curriculum and assessment documentation practice in the early childhood setting.

\section{- Secondary Data}

Secondary and archival data can be used to further facilitate the comprehensiveness of the data collection process, help in understanding of results, allowing better cross-cultural and crossnational comparability and generalisability (Schensul et al., 2013; Serra, 2016). Secondary data from local reports on general demographic, cultural, linguistic and socioeconomic characteristics of the research community and other specific areas of the population of interest to researchers may also be available from local archival data (Serra, 2016). One purpose of using secondary and document data is in helping to bridge or fill the research gap and in grounding theory development.

There are a number of possible sources for secondary data (Curtis, 2018; Peyrefitte \& Lazar, 2018; Serra, 2016)Sources include governmental sources and international agencies such as the UN or UNESCO and private international projects such as that by the European Union. The data from private entities and agencies, however, should be used with caution as not all private research is dedicated to objective scientific research. The use of newsletters, internet and social media posts, magazines and visual data from various sources are also be a sources of secondary documentary data (Bowen, 2009; Curtis, 2018; Serra, 2016). The findings will be discussed next.

\section{Findings and Discussion}

The findings from the study will be discussed in a number of themes or categories:
i) Future oriented practice
ii) The national curriculum framework
iii) International influences and approaches
iv) Pedagogical Documentation
v) Collaborative partnerships 


\section{Future-oriented practice}

The findings from the across the different data sets in this study demonstrate a spectrum of practices that define the enactment of the curriculum as implemented by early childhood teachers in the sector. From the 'snapshots' of enactment of the curriculum and the conversations with some of the practitioners within these early education settings, varied approaches have been adopted to enacting the curriculum have been adopted. It is apparent that these varied approaches form a 'blended' hybrid pedagogy that include inquiry-based, projectbased and experiential learning experiences, thereby validating the findings of other research studies (Chen et al., 2017; Lin, 2014). Following current international trends in early childhood educational pedagogy, there has been an increased emphasis on creativity, critical thinking and sustainability in early education in the country(Brown, 2019; MacDonald, 2015; New, 2015).

In the use of secondary data through social media sites within the first phase of study, one the thematic codes that emerged during the analysis and coding of the data was 'experiential/authentic learning' that referred to activities that were hands-on and engaging in real-life situations (Vartuli, Snider, \& Holley, 2016). These were 'real life' experiences and often brough the learners outside the classroom settings in field trips, excursions and activities such as a visit a hydroponic or frog farm, involving themselves in hands-on practical experiments with light and colour, all of which form aspects of the enacted curriculum. Although this was just $5.9 \%$ of the 19 thematic codes used and there was an overlap of category codes such as 'Discovery of the World', 'Cognitive Development/Skills' or 'Performance based learning'. The social media sites of the two centres with the highest frequencies of activities that was coded into 'authentic/experiential learning' was Amber and Opal and these frequencies constituted $32 \%$ and $35 \%$ of the total frequency counts for the social media sites for the five centres. 
Data from the exploratory observations, work sample and photo-elicited conversations with teachers showed that one of the approaches used was the language experience approach (LEA) (Ferlazzo \& Hull, 2018) where the children are encouraged to talk about and then use their emergent drawing and writing skills to express their own personal and shared practical experiences. This would evidently be part of the experiential education approaches that are being implemented in these centres. Another growing trend that may form part of a ReggioEmilia-inspired curriculum and also an adaptation of the 'Experiential Education' curriculum is that of the use of the project approach (Gardner, 2006; Gencer \& Gonen, 2015). Although this was not particularly highlighted in the five social media sites of the centres, it was something that was brought up time and again when talking of 'activities' that engaged the learners in shared sustained thinking and collaborative work (Devjak, Bercnik, \& Devjak, 2010; Purdon, 2016)

\section{The national curriculum framework}

More specific to the Singapore context, based on the curriculum policy document (NEL) and initiative which has been endeavoured to make learning experiences in early childhood education settings that engage the child in 'purposeful play' and with an emphasis on childcentred strategies (MOE, 2013). Based on the six learning domains articulated by the NEL curriculum framework (MOE, 2013), the curricular priorities have been examined by earlier research studies (Bautista et al., 2016) and also in this study where practitioners have expressed their belief that social-emotional competencies and self-care are particularly highlighted as one particular critical dimension of school readiness. Experienced practitioners in the sector have expressed the need to move away from a 'prescriptive' approach to the curriculum to a more reflective and progressively evolving strategy that requires teachers to 'walk the talk' while at the same time be actively creating the emergent curriculum in their classrooms. 
Arising from the use of internet-generated data from the social media sites of five early childhood education settings, several observations can be made through the interpretation of the ethnographic observations and conversations. A number of patterns and forms of pedagogy and practice are observed in these settings within the early childhood sector in the Singapore context. Engagement in activities that could be categorized with the six learning domains of the NEL framework (MOE, 2013) was well-represented in these social media sites. Outside this classification, the most frequently coded practices found in these sites were 'Approaches to learning', 'Community partnerships' and 'Authentic-experiential learning'. The social media sites of the selected five centres were purposefully sampled representing 'critical case' examples. Certain practices were highlighted in each of these social media sites. For example, Centre 'Pearl' and 'Emerald' were particularly well represented by 'Community Partnerships' while 'Culturally Responsive' strategies were particularly well represented in Centre 'Emerald'. Other aspects of the curriculum that were found represented in these social media sites included 'Environmental Awareness and Sustainability', 'Developmentally Appropriate Practice', 'Parent Partnerships', 'Performance based learning', 'Project based learning', 'Technologies' and 'Transitions. The example of a critical case in demonstrating culturally responsive approaches such as managing cultural diversity with 'local funds of knowledge' was 'Emerald'. The social media site of this centre demonstrated the integrated the use of community resources and the cultural capital arising from the diverse ethnicity enrolment at the centre.

\section{International approaches and Influences}

The findings based on the observations, interviews and survey indicate that teachers in Singapore are influenced by key international approaches to the early childhood curriculum. These include a few of the curricular models for pedagogical practice as outlined by the OECD report 'Starting Strong: Curricular and Pedagogies in Early Childhood Education and Care' 
(OECD, 2004). From the findings of both qualitative and quantitative phases, it is evident that a number of combination of approaches and strategies have been put into practice in implementing the curriculum. There are observed many similarities that centres have strived to put into practice and adopt that are found in major curricula approaches. In the survey, the other key approaches that were listed in eliciting what early childhood teachers were familiar with and what they practiced were the Montessori method (MM) and the use of the Multiple Intelligences theory (MI). These were $33.7 \%$ (familiarity) and $12 \%$ (practice) for the Montessori Method and 31.5\% (familiarity) and 16.3\% (practice) for the MI approach respectively. The approaches that the teachers indicated they were most familiar with in this survey was the NEL(77.2\%), $\operatorname{EYDF}(70.7 \%)$ and Reggio Emilia-inspired (37\%)) approaches. A number of other approaches that include literacy- (Ferlazzo \& Hull, 2018) and play-based approaches (Niland, 2009), the IB-PYP continuum (Morrissey, Rouse, Doig, Chao, \& Moss, 2014), Nordic Steiner approach (Boland, 2015) , Orff Kodaly and Dalcroze (Doç \& Göktürk, 2012) and more centre specific curricula were also listed by survey participants in the 'Others' category. However, at least $72.8 \%$ of survey participants indicated that they referred to the NEL framework at least to a 'moderate amount' in their practices. The findings from the survey participants corroborated with interview findings in that the national curriculum framework (MOE, 2013) formed the core basis and foundation for the majority of early childhood teachers in Singapore in their practice and delivery of the curriculum in their centres. However, the number of a variety of other more 'internationalized' approaches and strategies have been brought into early childhood settings in Singapore which supports the trend towards more 'hybrid' and 'blended' curricula.

In the survey, with the question asked about how much individual practitioners consider 'children's interests', the response for 'a great deal' and 'a lot' made up 71.7\% of the total responses. This suggests that much of the curriculum is quite child-centred which is a similar 
philosophy to the Reggio Emilia-inspired approach (Press, Wong, \& Sumsion, 2012). The survey findings indicate that a large percentage of early childhood practitioners are familiar with the national curriculum frameworks (ECDA, 2013; MOE, 2013) while a smaller proportion are familiar with internationalized approaches that include the Reggio-Emilia inspired, the Montessori method, the multiple intelligences theory as well as approaches that were specific to their centres or particular discipline. There is a relatively open policy in allowing early learning centres to be receptive to an influx of external influences locally, regionally and globally while the local national curriculum framework (NEL) provides the preliminary starting points for initial teacher education.

As change does not involve only official policy change initiatives, it also involves changing mindsets as well as the attitudes, values and beliefs of both educators and parents. The process has evolved over a period of time and hence the challenge in narrowing the gap between the intended and the enacted curriculum (Bauml, 2016). Teachers' readiness to embrace change is also a significant factor in determining the successful enactment and implementation of the intended curriculum (Walsh \& Gardner, 2006).

\section{Pedagogical documentation}

The concept of constructing a more child-centred pedagogy and nurturing learner identities through pedagogical documentation has been promoted international research literature (Biffi, 2019; Chng, 2019). In practice, the process may vary in different cultural and national contexts and the NEL framework provides some guidelines in this process specific to the context of Singapore. Pedagogical documentation has also been demonstrated as a strategy that enables teachers as professionals, facilitating communication with parents and learners, as well as other educators (Rintakorpi, 2016). With the several forms of pedagogical documentation, particularly in the use of the portfolio, some aspects of its purpose may be considered different from the original Reggio Emilia approach. In 'The Hundred Languages of Children', Dahlberg 
(2011) highlights the use of pedagogical documentation that promotes the school as a public space where democratic political practice enables participants to engage in a variety of issues and practices and visualize and negotiate dominant discourses.

With regards to the use of portfolios in the survey, 36.3\% of participants indicated that 'Children use earlier work to make self-evaluation of their own achievement' and respondents were allowed to indicate more than one purpose, the percentage indicating other forms of involvement of children with their portfolios such as 'deciding what work samples are used' (20.9\%), revisit their portfolios' (23.1\%) and 'setting their learning goals'(11\%) were slightly smaller. However, almost $26.4 \%$ of the respondents who indicate 'Other' purposes specified that children did not directly use or were involved in the processes of the portfolio. Conversations and observations in centre settings also appear to reinforce the fact that portfolio documentation was mainly to provide parents more information and updates about what was happening in the school-centre setting and to provide a portal for discussion between parents and teachers. It also provides a way to inform other teacher educators about what the child has 'achieved' and activities accomplished in the portfolio and some background for teacher when the child transitions into the following year. Whether it is used as a tool for research often depends on the centre-management philosophy and the teacher's own understanding of a Reggio-Emilia inspired approach (Edwards \& Gandini, 2015).

Another class used home-school project partnership approach and got parents to become involved in helping their child create the project with re-cycled materials. These projects were usually ongoing for at least one term of the full year so the processes of the initial provocation, brainstorming, experimentation, scaffolding and coming up with a final project was not hurried. A teacher also talked about being involved in a 'Water Conservation' project that her centre management had got them involved in the brainstorming, planning and documentation of the project processes that was funded by the government's ECDA Innovation Project Grant. From 
the teachers' interviews and general observations in the field, there were role models and educators who understand the value and importance of the policies, practices and educational philosophies that nurture and develop the agency of children that preserve the culture of sustainability (Thornton \& Cherrington, 2018). These findings suggest that their critical part in their roles in bringing out the child's voice and input into the daily curriculum and through the processes of the inquiry or project approach set up the provocations and stimulus to inspire the young learners to be active participants and constructors of their own learning experiences (Weldemariam et al., 2017). Experiential education has been viewed as a holistic education approach that requires learners to engage in reflection, critical analysis and synthesis, as well explore, experiment, problem-solve and construct meaning (Smith, Knapp, Seaman, \& Pace, 2010)

\section{Collaborative partnerships}

Communal responsibility and collaboration, particularly with the parents, families and the community is a strong feature of the Reggio-Emilia approach (Devjak et al., 2010). These values are shared by many local centres in Singapore. In this study, the internet-based data provided additional corroboration and evidence in supporting the emphasis and value of communal responsibility and collaboration. Although this is only visually represented with $6.3 \%$ of social media posts featuring community partnerships and $5 \%$ highlighting parent involvement and partnerships overall amongst the 19 code categories, two of the five centres featured particularly strongly in community and family partnerships. The small percentage indicated in social media posts does not imply that there is little parental engagement because not all interactions and activity is visually documented in these social media posts. Centre 'Emerald' representation of parent partnerships and involvement was 42\% (11/26) and for community partnerships, it was $39 \%(13 / 33)$ of the total representation by the five centres. Centre 'Opal' had a representation of 23\% (6/26) for parent partnerships and 30\% (10/33) of the 
total representation by the five centres. From the interviews, teacher participants appear to strongly believe in the need for parental involvement and engagement with the child's learning experience although there was some indication that 'Asian' parents tend to have rather performance-oriented goals for their child. Centre practices often involve organizing various family events, activities and even workshops for parents so as to involve parents in their children's learning and progress . In the survey as well, $71.8 \%$ of teacher participants indicated that they involve parents from at least a moderate amount to 'a great deal' when planning and implementing the curriculum. The exact forms of parental involvement appears varied based on interview findings and ranged from parents attending workshops and events that their children were engaged in to parents providing feedback and working with teachers to support the child's learning experience as in home-school projects (Bush, Eisenhower, Cohen, \& Blacher, 2017; Frewen, Chew, Carter, Chunn, \& Jotanovic, 2015).

\section{Summary}

The use of a mixed methods approach that included visual netnography, ethnographic observations with participant-generated data, as well as a survey questionnaire provided complementary findings about various aspects and dimensions of the processes of enactment of the curriculum in Singapore early childhood education settings (Morgan, 2014; Tashakkori $\&$ Teddlie, 2010). Findings from the initial qualitative phase of the study was used to shape and develop the survey instrument in the subsequent phased of the study (Creswell \& Plano Clark, 2017). In grounding interpretations and conclusions in multiple perspectives through multiple participants, methods and philosophical worldviews, there is an increase validity of the findings and conclusions (Guba \& Lincoln, 2005; Mertens, 2010).

The consolidated findings in this study show that teachers often use a hybrid blend of local as well as 'internationalized' practices in the delivery of the curriculum. In this particular context, although the national curriculum framework provides the framework and guidelines for 
learners up to the age of six, there are many influences and international models that have been 'imported' (Yang \& Li, 2019) and also impacted practices. This is not a surprising trend that is an ongoing consequence of globalization and the exchange of information and knowledge across borders (Faas \& Wasmuth, 2019; Gupta, 2015). These findings parallel those of others who have identified that curriculum development, teaching professionalism and educational policy have also be transformed in the context of globalization (Pascal, Bertram, \& Veisson, 2018; Zajda, 2015).

\section{References}

Addeo, F., Delli Paoli, A., Esposito, M., \& Ylenia Bolcato, M. (2019). Doing Social Research on Online Communities: The Benefits of Netnography. Athens Journal of Social Sciences, 7(1), 9-38. https://doi.org/10.30958/ajss.7-1-1

Agarwal, N. K. (2011). Verifying survey items for construct validity: A two-stage sorting procedure for questionnaire design in information behavior research. Proceedings of the ASIST Annual Meeting, 48. https://doi.org/10.1002/meet.2011.14504801166

Atkinson, R. (2002). The Life Story Interview. In J. F. Gubrium \& J. A. Holstein (Eds.), Handbook of Interview Research. Thousand Oaks, California: Sage Publications.

Ballesteros, B., \& Mata-benito, P. (2018). The Inner Process of Collective Interpretation in Qualitative Research. The Qualitative Report, 23(1), 168-183. https://doi.org/10.1007/s00125-006-0227-2

Bauml, M. (2016). One size never fits all: Teachers' responses to standardized curriculum materials and implications for early childhood teacher educators. Journal of Early Childhood Teacher Education, 37(1), 76-95. https://doi.org/10.1080/10901027.2015.1133461

Bautista, A., Ng, S.-C., Múñez, D., \& Bull, R. (2016). Learning areas for holistic education: kindergarten teachers' curriculum priorities, professional development needs, and beliefs. In International Journal of Child Care and Education Policy. https://doi.org/10.1186/s40723-016-0024-4

Bautista, A., Wong, J., \& Gopinathan, S. (2017). Teacher Professional Development in Singapore: Depicting the Landscape. Psychology, Society, \& Education, 7(3), 311. https://doi.org/10.25115/psye.v7i3.523

Biffi, E. (2019). Pedagogical documentation as a shared experience of understanding childhood. In J. Formosinho \& J. Peeters (Eds.), Understanding Pedagogic Documentation in Early Childhood Education : Revealing and Reflecting on High Quality Learning and Teaching (pp. 67-80). https://doi.org/10.4324/9780429030055-5

Boland, N. (2015). The globalisation of Steiner education : Some considerations. 6, 192-202. Retrieved from http://www.enastecongress.net/powerpoints-congress/content_gdianct/Neil-Boland.pdf

Bowen, G. A. (2009). Document Analysis as a Qualitative Research Method. Qualitative Research Journal, 9(2), 27-40. https://doi.org/10.3316/QRJ0902027

Brinkmann, S. (2013). Qualitative interviewing: Understanding qualitative research. New York, USA: Oxford University Press.

Brown, N. (2019). Internationalizing the Early Childhood Curriculum: Foundations of Global Competence. 
Abington:Oxon: New York: Routledge; Taylor \& Francis.

Bush, H. H., Eisenhower, A. S., Cohen, S. R., \& Blacher, J. (2017). Parents' educational expectations for young children with autism spectrum disorder. Education and Training in Autism and Developmental Disabilities, 52(4), 357-368.

Chen, J. J., Li, H., \& Wang, J. ying. (2017). Implementing the Project Approach: A Case Study of Hybrid Pedagogy in a Hong Kong Kindergarten. Journal of Research in Childhood Education, 31(3), 324-341. https://doi.org/10.1080/02568543.2017.1309479

Chng, A. (2019). Seeing through pedagogical documentation. In A. Salamon \& A. Chng (Eds.), Multiple Childhood Identities. Taylor and Francis.

Christ, T. W. (2013). The worldview matrix as a strategy when designing mixed methods research. International Journal of Multiple Research Approaches, 7(1), 110-118. https://doi.org/10.5172/mra.2013.7.1.110

Clark, V. L. P., \& Ivankova, N. V. (2018). Why use Mixed Methods Research?: Identifying Rationales for Mixing Methods. In Mixed Methods Research: A Guide to the Field (pp. 79-104). https://doi.org/10.4135/9781483398341.n7

Creswell, J. (2014). Research design: Qualitative, quantitative and mixed methods approaches. (4th, Ed.). Thousand Oaks: Sage Publications.

Creswell, J. (2015). A concise introduction to mixed methods research. (Sage Mixed). Los Angelas: SAGE.

Creswell, J., \& Plano Clark, V. (2011). Designing and conducting mixed methods research. (2nd ed.). Los Angelas: Sage Publications.

Creswell, J., \& Plano Clark, V. (2017). Designing and conducting mixed methods. (Third, Ed.).

Crotty, M. (1998). The foundations of social research : Meaning and perspective in the research process. St. Leonards, NSW: Allen and Unwin.

Crouch, M., \& McKenzie, H. (2006). The logic of small samples in interview-based qualitative research. Social Science Information, 45(4), 483-499. https://doi.org/10.1177/0539018406069584

Curtis, B. (2018). Secondary Research: Repurposing Data. Secondary Research: Repurposing Data. https://doi.org/10.4135/9781526461841

Denscombe, M. (2008). Communities of Practice: A Research Paradigm for the Mixed Methods Approach. Journal of Mixed Methods Research, 2(3), 270-283. https://doi.org/10.1016/B978-0-08-097086-8.920518

Denscombe, M. (2010). The good research guide for small-scale social research projects. (4th ed.). Glasgow: Great Britain: Open University Press.

Devjak, T., Bercnik, S., \& Devjak, S. (2010). Introducing Special Educational Principles of Reggio Emilia Concept in Slovene Curricuclum for Preschool Eduction. 3Rd International Conference of Education, Research and Innovation (Iceri2010), 88-95. https://doi.org/10.1007/bf01170806

Dewey, J. (2008). Reconstruction in philosophy. In J. Boydston \& R. Ross (Eds.), The middle works of John Dewey 1899-1924 (vol.12 pp 77-202). Carbondale: Southern Illinois University (Original work published in 1920).

Doç, Y., \& Göktürk, D. (2012). Kodaly and Orff: A comparison of two approaches in early music education. Journal of Social Sciences, 8(15).

ECDA. (2013). Early Years Development Framework for Child Care Centres (EYDF). Retrieved from https://www.ecda.gov.sg/Educators/Pages/Early-Years-Development-Framework-(EYDF)-EducarersGuide.aspx

Edmonds, W. A., \& Kennedy, T. D. (2013). An applied reference guide to research designs: Quantitative, qualitative and mixed methods.

Edwards, C. P., \& Gandini, L. (2015). Teacher research in Reggio Emilia, Italy: Essence of a dynamic, evolving role. Faculty Publications, Department of Child, Youth and Family Studies, 
https://digitalcommons.unl.edu/famconfacpub/105. Retrieved from http://digitalcommons.unl.edu/famconfacpubhttp://digitalcommons.unl.edu/famconfacpub/105

Faas, S., \& Wasmuth, H. (2019). Globalization, transformation and cultures in early childhood education and care: Reconceptualization and Comparison (Stefan Faas, D. Kasüschke, E. Nitecki, M. Urban, H. Wasmuth, \& M. Bloch, Eds.). Cham: Springer Nature Switzerland.

Ferlazzo, L., \& Hull, K. (2018). Language Experience Approach ( LEA ). In The ELL Teacher's toolbox: Hundreds of Practical Ideas to Support Your Students (pp. 87-90). San Francisco: John Wiley \& Sons Inc.

Frewen, A. R., Chew, E., Carter, M., Chunn, J., \& Jotanovic, D. (2015). A cross-cultural exploration of parental involvement and child-rearing beliefs in Asian cultures. Early Years, 35(1), 36-49. https://doi.org/10.1080/09575146.2014.956294

Gardner, H. (2006). Projects During the Elementary Years. In Multiple Intelligences: New Horizons in Theory \& Practice (pp. 113-122). New York: Basic Books: Perseus Group.

Gencer, A. A., \& Gonen, M. (2015). Examination of The Effects of Reggio Emilia Based Projects on Preschool Children's Creative Thinking Skills. Procedia - Social and Behavioral Sciences, 186(312), 456-460. https://doi.org/10.1016/j.sbspro.2015.04.120

Grand, von Arx, R.-S. (2015). Constructivist paradigms: Implications for strategy-as-practice research. In D. Golsorkhi, L. Rouleau, D. Seidl, \& E. Vaara (Eds.), Cambridge Handbook of Strategy as Practice, (Second, pp. 78-94). https://doi.org/10.1017/CCO9781139681032.005

Greene, J. C., \& Hall, J. N. (2010). Dialectics and pragmatism: Being of consequence. In A. T. \& C. Teddlie (Ed.), Sage handbook of mixed methods in social and behavioural research (2nd ed.). Thousand Oaks, California: SAGE.

Guba, E. G., \& Lincoln, Y. S. (2005). Paradigmatic controversies, contradictions and emerging influences. In N. K. Denzin \& Y. S. Lincoln (Eds.), The Sage Handbook of Qualitative Research (Third). London: Sage Publications.

Gupta, A. (2015). Pedagogy of third space: A multidimensional early childhood curriculum. Policy Futures in Education, 13(2), 260-272. https://doi.org/10.1177/1478210315579540

Hacking, I. (1999). The Social Construction of What? Cambridge MA: Harvard University Press.

Halldén, O., Haglund, L., \& Strömdahl, H. (2007). Conceptions and contexts: On the interpretation of interview and observational data. Educational Psychologist, 42(1), 25-40. https://doi.org/10.1080/00461520709336916

Johnson, R. B., \& Stefurak, T. (2013). Considering the evidence-and-credibility discussion in evaluation through the lens of dialectical pluralism. New Directions for Evaluation, 37-48.

Johnson, R. Burke, \& Onwuegbuzie, A. J. (2004). Mixed Methods Research: A Research Paradigm Whose Time Has Come. Educational Researcher, 33(7), 14-26. https://doi.org/10.3102/0013189X033007014

Keller, C., Fleury, J., Perez, A., Ainsworth, B., \& Vaughan, L. (2008). Using visual methods to uncover context. Qualitative Health Research, 18(3), 428-436. https://doi.org/10.1177/1049732307313615

Kortegast, C. A., McCann, K., Branch, K., Latz, A. O., Kelly, B. T., \& Linder, C. (2019). Enhancing ways of knowing: The case for utilizing participant-generated visual methods in higher education research. Review of Higher Education, 42(2), 485-510. https://doi.org/10.1353/rhe.2019.0004

Kozinets, R. (2006). Chapter 10: Netnography 2.0. The Handbook of Qualitative Research Methods in Marketing, 129-142. https://doi.org/10.4337/9781847204127.00018

Liebenberg, L. (2009). The visual image as discussion point: Increasing validity in boundary crossing research. Qualitative Research, 9(4), 441-467. https://doi.org/10.1177/1468794109337877

Lin, Y.-S. (2014). A third space for dialogues on creative pedagogy: Where hybridity becomes possible. Thinking Skills and Creativity, 13(2), 43-56. https://doi.org/10.1016/j.tsc.2014.03.001

Literat, I. (2013). “A pencil for your thoughts": Participatory drawing as a visual research method with children 
and youth. International Journal of Qualitative Methods, 12(1), 84-98. https://doi.org/10.1177/160940691301200143

MacDonald, M. (2015). Early Childhood Education and Sustainability: A Living Curriculum. Childhood Education, 91(5), 332-341. https://doi.org/10.1080/00094056.2015.1090845

Mertens, D. M. (2007). Transformative Paradigm: Mixed Methods and Social Justice. Journal of Mixed Methods Research, 1(3), 212-225. https://doi.org/10.1177/1558689807302811

Mertens, D. M. (2010). Philosophy in Mixed Methods Teaching. International Journal of Multiple Research Approaches, 4(1), 9-18.

Mertens, D. M. (2015). Philosophical Assumptions and Program Evaluation. Spaziofilosofico, 75-85.

Mitchell, L. (2008). Assessment practices and aspects of curriculum in early childhood education. Wellington, New Zealand.

MOE. (2013). Nurturing Early Learners: Educator's Guide (Overview) (Vol. 1). Ministry of Education, Singapore.

Morgan, D. L. (2007). Paradigms Lost and Pragmatism Regained: Methodological Implications of Combining Qualitative and Quantitative Methods. Journal of Mixed Methods Research, 1(1), 48-76. https://doi.org/10.1177/2345678906292462

Morgan, D. L. (2014). Pragmatism as a Paradigm for Social Research. Qualitative Inquiry, 20(8), 1045-1053. https://doi.org/10.1177/1077800413513733

Morrissey, A.-M., Rouse, E., Doig, B., Chao, E., \& Moss, J. (2014). Early Years Education in the Primary Years Programme (PYP): Implementation Strategies and Programme Outcomes Final Report International Baccalaureate Organisation.

New, R. S. (2015). 21 st CENTURY EARLY CHILDHOOD TEACHER New Frames for a Shifting Landscape. In L. J. Couse \& S. L. Recchia (Eds.), Handbook of Early Childhood Teacher Education (pp. 3-19). New York: Routledge.

Niland, A. (2009). The Power of Musical Play: The Value of Play-Based, Child-Centered Curriculum in Early Childhood Music Education. General Music Today, 23(1), 17-21. https://doi.org/10.1177/1048371309335625

O'Connell, R. (2013). The use of visual methods with children in a mixed methods study of family food practices. International Journal of Social Research Methodology, 16(1), 31-46. https://doi.org/10.1080/13645579.2011.647517

OECD. (2004). Starting Strong Curricula and Pedagogies in Early Childhood Education and Care. Paris.

Ong, P. A. L. (2019). Teachers Perspectives and the Enacted Curriculum:The dialogic space for pedagogical hybridity in the ECE curriculum. NZARE 2019 University of Canterbury (19th-21st Nov 2019). Christchurch, New Zealand.

Onwuegbuzie, A. J. (2012). Puting the MIXED back into quantitative and qualitative research in educational research and beyond: Moving toward the radical middle. International Journla of Multiple Research Approaches, 6(3), 192-219.

Pascal, C., Bertram, T., \& Veisson, M. (2018). Early Childhood Education and Change in Diverse Cultural Contexts.

Peyrefitte, M., \& Lazar, G. (2018). Student-centered Pedagogy and Real-world Research: Using Documents as Sources of Data in Teaching Social Science Skills and Methods. Teaching Sociology, 46(1), 62-74. https://doi.org/10.1177/0092055X17727835

Pfister, A. E., Vindrola-Padros, C., \& Johnson, G. A. (2015). Together, We Can Show You. Collaborative Anthropologies, 7(1), 26-49. https://doi.org/10.1353/cla.2014.0005

Phillips, D. C. (Denis C. (2000). Postpositivism and educational research [electronic resource]. 2001.

Pink, S. 1. (2007). “Visual Methods.” Qulitative Research Pratice., 361-376. https://doi.org/10.1109/61.568259 
Pink, Sarah. (2011). The Visual in Ethnography: Photography, Video, Cultures and Individuals. In Doing Visual Ethnography (pp. 21-39). https://doi.org/10.4135/9780857025029.d4

Press, F., Wong, S., \& Sumsion, J. (2012). Child-Centred, Family-Centred, Decentred: Positioning Children as Rights-Holders in Early Childhood Program Collaborations. Global Studies of Childhood, 2(1), $26-37$. https://doi.org/10.2304/gsch.2012.2.1.26

Purdon, A. (2016). Sustained shared thinking in an early childhood setting: an exploration of practitioners' perspectives. Education 3-13, 44(3), 269-282. https://doi.org/10.1080/03004279.2014.907819

Reissner, S. C. (2017). Interactional Challenges and Researcher Reflexivity: Mapping and Analysing Conversational Space. European Management Review, 15, 205-219. https://doi.org/10.1111/emre.12111

Rintakorpi, K. (2016). Documenting with early childhood education teachers: pedagogical documentation as a tool for developing early childhood pedagogy and practises. Early Years, 36(4), 399-412. https://doi.org/10.1080/09575146.2016.1145628

Ryan, B. A. (1999). Does postmodernism mean the end of science in the behavioural sciences and does it matter anyway? Theory \& Psychology, 9, 483-502.

Schensul, S. L., Shensul, J. J., \& LeCompte, M. D. (2013). Essential ethnographic methods: Observations, interviews and questionnaires. Cumnor Hill, Oxford, UK: AltaMira Press: Rowman \& Littlefield Publishers Inc,.

Serra, F. A. R. (2016). Secondary Data in Research - Uses and Opportunities. Iberoamerican Journal of Strategic Management, 25(2), 17-18. https://doi.org/10.2307/3385333

Shannon-Baker, P. (2016). Making Paradigms Meaningful in Mixed Methods Research. Journal of Mixed Methods Research, 10(4), 319-334. https://doi.org/10.1177/1558689815575861

Shannon-Baker, P., \& Edwards, C. (2018). The Affordances and Challenges to Incorporating Visual Methods in Mixed Methods Research. American Behavioral Scientist, 62(7), 935-955. https://doi.org/10.1177/0002764218772671

Smith, T. E, Knapp, C. E., Seaman, J., \& Pace, S. (2010). Experiential Education and Learning by Experience. In Thomas E. Smith \& C. E. Knapp (Eds.), Sourcebook of Experiential Education: Key Thinkers and their Contributions (pp. 1-12). Taylor \& Francis Group.

Stocchetti, M. (2017). Digital visuality and social representation. Research notes on the visual construction of meaning. Kome, 5(2), 1-19. https://doi.org/10.17646/KOME.2017.23

Tashakkori, A., \& Teddlie, C. (2010). SAGE handbook of mixed methods in social and behavioural research. https://doi.org/10.4135/9781506335193

Thornton, K., \& Cherrington, S. (2018). Professional learning communities in early childhood education: a vehicle for professional growth. Professional Development in Education, 00(00), 1-15. https://doi.org/10.1080/19415257.2018.1529609

Tracy, S. J. (2013). Qualitative research methods: Collecting evidence, crafting analysis, communicating impact. West Sussex, UK: Blackwell Publishing: John Wiley \& Sons.

Vartuli, S., Snider, K., \& Holley, M. (2016). Making it Real: A Practice-Based Early Childhood Teacher Education Program. Early Childhood Education Journal, 44(5), 503-514. https://doi.org/10.1007/s10643015-0733-2

Walsh, G., \& Gardner, J. (2006). Teachers' readiness to embrace change in the early years of schooling: A northern ireland perspective. International Journal of Phytoremediation, 21(1), 127-140. https://doi.org/10.1080/13502930285209961

Weldemariam, K., Boyd, D., Hirst, N., Sageidet, B. M., Browder, J. K., Grogan, L., \& Hughes, F. (2017). A Critical Analysis of Concepts Associated with Sustainability in Early Childhood Curriculum Frameworks Across Five National Contexts. International Journal of Early Childhood, 49(3), 333-351. https://doi.org/10.1007/s13158-017-0202-8

Wenger, E. (1999). Communities of Practice: Learning, Meaning and Identity. Cambridge: Cambridge University Press. 
Wenger, E. (2001). Communities of Practice. International Encyclopedia of the Social \& Behavioral Sciences, 2339-2342. https://doi.org/10.1016/b0-08-043076-7/00361-2

Willis, J. (2012). Foundational Issues: Postpositivist and Critical Perspectives. Foundations of Qualitative Research: Interpretive and Critical Approaches, 67-94. https://doi.org/10.4135/9781452230108.n3

Willis, R. (2019). The use of composite narratives to present interview findings. Qualitative Research. https://doi.org/10.1177/1468794118787711

Yang, W., \& Li, H. (2019). Early childhood curriculum as a cultural practice. In Early Childhood Curriculum in Chinese Societies (pp. 121-132). https://doi.org/10.4324/9781351027267-9

Zajda, J. (Ed.). (2015). Second International Handbook on Globalisation, Education and Policy Research. Springer. 